\title{
PATERN AND TREND OF INTERNET ADDICTION DISORDER AMONG MEDICAL STUDENTS IN ALEXANDRIA: A CROSS SECTIONAL STUDY
}

Hoda Ghareeb Mohamed, Ghada Abdel Hady Ashmawy*, Hend Ibrahim Ibrahim Kamel

Department of Community Medicine, Department of Neuro-psychiatry*, Alexandria Faculty of Medicine, Egypt

\section{Introduction}

The Internet itself is designed to facilitate research among academic \& military agencies. The internet usage has been rapidly increasing worldwide nd has become an integral part of day-to-day life. College students are vulnerable because of the psychological and developmental characteristics of late adolescence \& ready access to the internet. The internet addiction disorder (IAD) is a new kind of mental illness characterized by excessive, constant and misuse of the internet recognized by adverse reaction and compulsive behavior. Accordingly, familial, academic and occupational problems are the negative consequences.

\section{Aims of the work}

To reveal the prevalence, pattern and trend of IAD among Alexandria medical students.

\section{Subjects and Methods}

Research strategy:

In order to achieve the research objectives, a cross-sectional study was In order to
carried out

Research settings:

Faculty Of Medicine, Alexandria University during the academic year 2018/2019.

Target population:

Consented stratified sample of 400 medical students, with equal allocation, at different grades including undergraduates (from 1st to 6th year and

intern) and postgraduates (fresh graduated tutors).
Data collection tools and methods

Self-administered semi-structured questionnaire consisting of data about: 1- Socio-demographic personal characters.

II-The Young's Internet Addiction Test (IAT) questionnaire for diagnosis of IAD.

\section{Results}

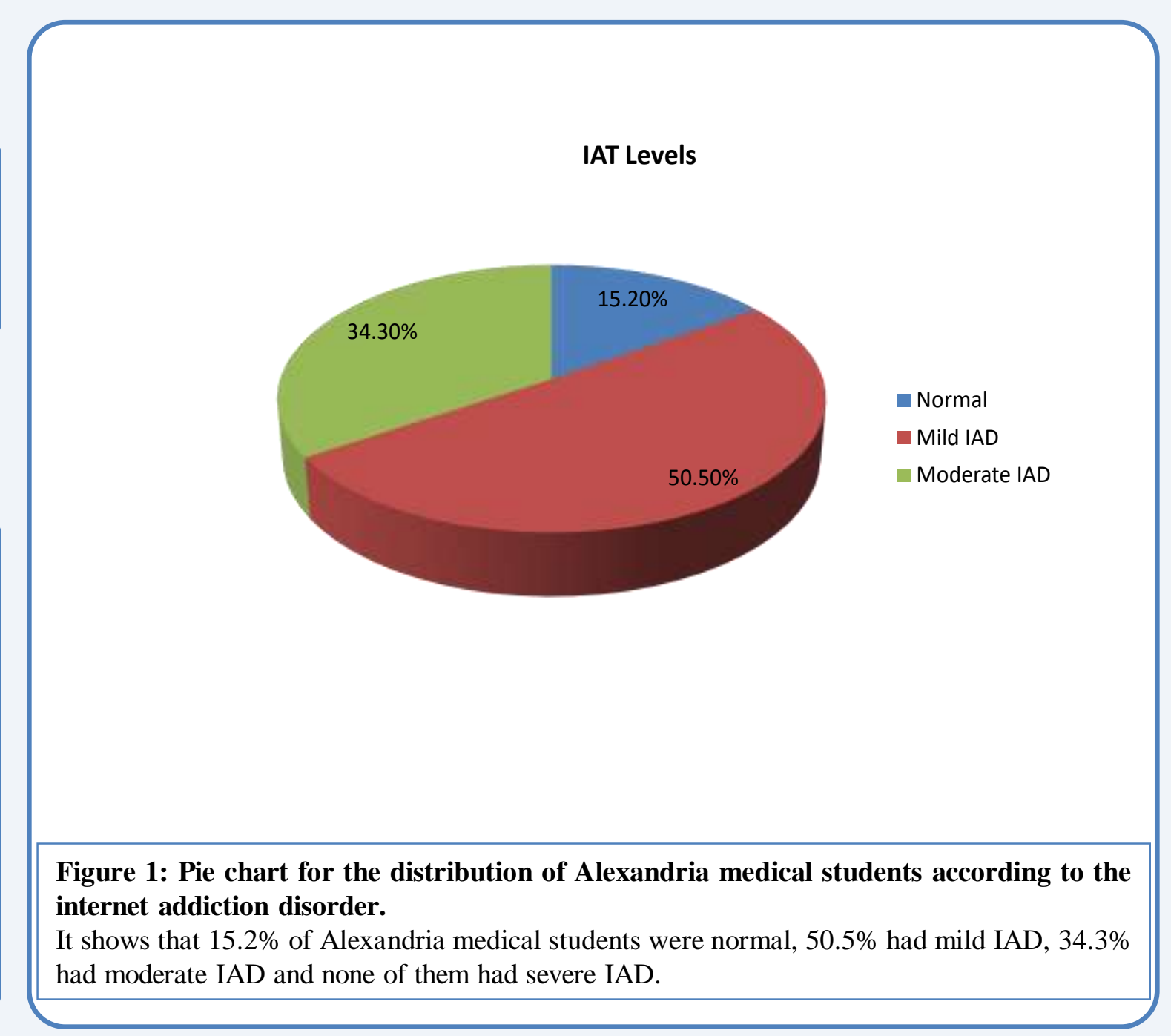

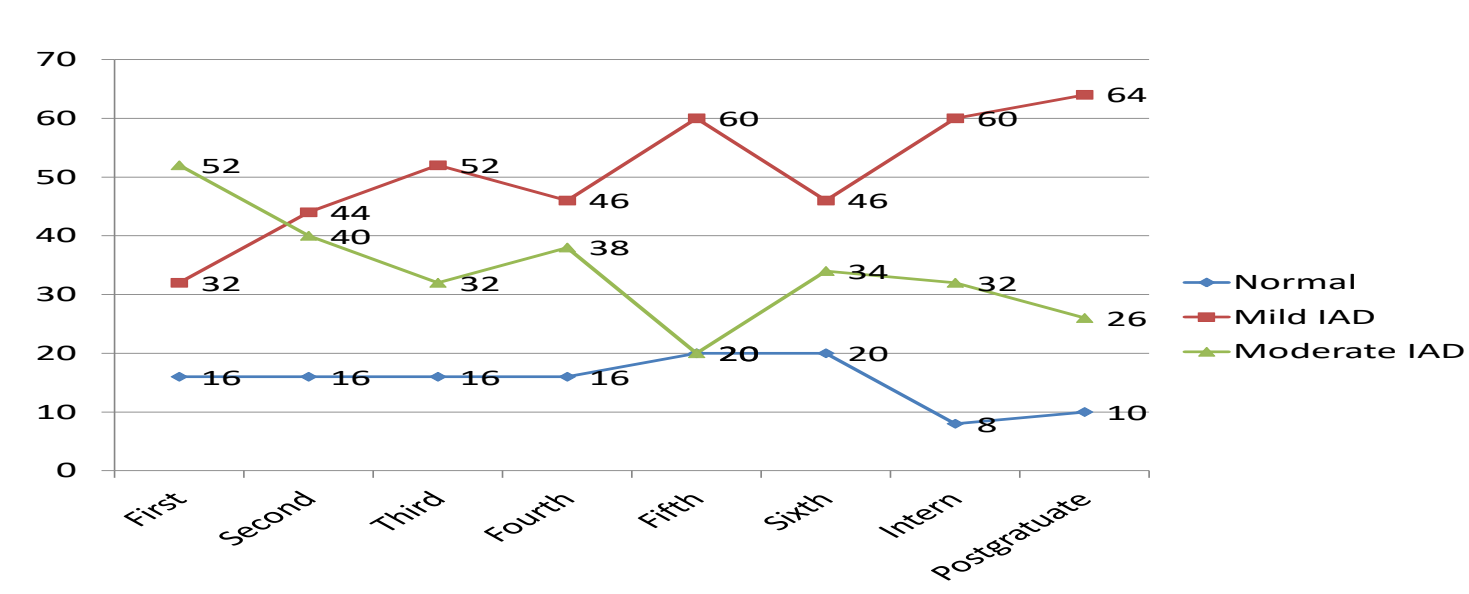

Figure 2: line graph for IAD trend i.e Comparison of the overall internet addiction test disorder levels regarding the undergraduates' grade, intern \& postgraduate Alexandria medical students. Moderate IAD was highest among $1^{\text {ts }}$ grade (52\%) and it was lowest among $5^{\text {th }}$ grade $(20 \%)$. Mild IAD was students were highest among $5^{\text {th }}$ and $6^{\text {th }}$ grades (20\% for each of them) and it was lowest among intern $(8 \%)$. There are no statistical significant differences $(\mathrm{P}=0.09)$.

\section{Conclusion}

The present study revealed that $84.8 \%(50.5 \%+34.3 \%)$ of the Alexandria Medical students had mild to moderate IAD, according to the study instrument of Young. This could be attributed to easy access to the Internet without parental control Moderate IAD was highest among $1^{\text {st }}$ grade $(52 \%)$ and the mild IAD was highest among postgraduates (64\%). This may be due to frequent use of the Internet to search for medical information as well as participating in online learning and assessment or to escape from academic stress. On the other hand, normal students were highest among $5^{\text {th }}$ and $6^{\text {th }}$ grades (20\% for each of them). This could be explained by the fact that final year students preparing for university exams and may be more serious with their studies.

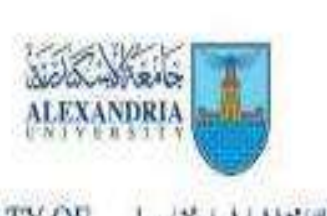

2019@Alexandria Faculty of Medicine FACUTY OP
MEDICINE 